\title{
Current and Proposed Treatment Strategies for Siewert Type II Adenocarcinoma of the Esophagogastric Junction
}

Kosuke Narumiya ( $\nabla$ narumiya.kosuke@twmu.ac.jp )

Tokyo Women's Medical University

Kenji Kudo

Tokyo Women's Medical University

Yosuke Yagawa

Tokyo Women's Medical University

Shinsuke Maeda

Tokyo Women's Medical University

Yukinori Toyoshima

Tokyo Women's Medical University

Kyohei Ogawa

Tokyo Women's Medical University

Sho Izumika

Tokyo Women's Medical University

Harushi Osugi

Tokyo Women's Medical University

Hiroto Egawa

Tokyo Women's Medical University

\section{Research Article}

Keywords: Adenocarcinoma of the esophagogastric junction (AEG), Optimal lymph node resection, Neoadjuvant chemoradiotherapy, Lymph node station index, Esophageal involvement

Posted Date: January 3rd, 2022

DOI: https://doi.org/10.21203/rs.3.rs-1109377/v2

License: (c) (i) This work is licensed under a Creative Commons Attribution 4.0 International License.

Read Full License 


\section{Abstract}

\section{Background}

Incidence of adenocarcinoma of the esophagogastric junction (AEG) is increasing in Japan as well as Western Country. However, there is no consensus on treatment strategy. The purpose of this study was to determine the optimal range of resection and lymph node dissection for Siewert type II AEG and to develop a strategy for treatment that includes adjuvant therapy to improve the survival rate.

\section{Methods}

We retrospectively investigate 88 cases of advanced $A E G$ in patients who underwent surgery with lymph node dissection with 52 cases of superficial AEG, 23 of whom underwent endoscopic treatment (endoscopic mucosal resection [EMR] or endoscopic submucosal dissection [ESD]), and 29 of whom underwent surgery with lymph node dissection.

\section{Results}

The optimal lymph nodes to resect for advanced AEG were in the inferior mediastinum (No. 110), in the lesser curvature (Nos. 1, 3, 7), No. 2, and No 11. According to area of actual lymph node metastasis, lymphadenectomy of lymph nodes 1, 2, 3, 7, and 11 was sufficient to improve survival of patients with superficial AEG. If esophageal involvement was $>40 \mathrm{~mm}$, we performed esophagectomy through right thoracotomy. The 5-year overall survival rates were $88 \%$ for patients treated with ESD, $78 \%$ for those with superficial AEG who under-went surgery, and $24 \%$ for those with advanced AEG ( $p=0.011)$. Despite of lymph node dissection, twenty-five patients experienced lymph node metastasis after operation in advanced $A E G$ and there were many disseminations in advanced $A E G$. There were no differences in survival between patients who received postoperative adjuvant therapy with $S-1$ for advanced AEG and those who received surgery alone $(p=0.5192)$.

\section{Conclusion}

Although surgical procedures of superficial and locally advanced AEG are standardized, the role of adjuvant therapy for AEG is still controversial. We recommend nab-paclitaxel plus radiotherapy for advanced $A E G$ as neoadjuvant therapy.

\section{Introduction}

In the 1970s, squamous cell carcinoma accounted for most esophageal cancers in both Western nations and Japan, and adenocarcinoma accounted for only a small proportion. However, in Western countries, the increased incidence of Barrett esophagus, a condition that gives rise to esophageal adenocarcinoma, as well as the rising incidence of gastroesophageal reflux disease due to changes in dietary habits and obesity, led to adenocarcinoma's accounting for more than half of all cases of esophageal cancer in the 1990s [1, 2]. In Japan, the decreasing rate of Helicobacter pylori infection and the rise in obesity and 
reflux esophagitis have led to concerns about rising rates of esophageal cancer similar to those observed in Western countries. However, the number of cases in Japan is still insufficient to clearly identify this as a trend $[3,4]$. The optimal treatment strategy for Siewert type II adenocarcinoma of the esophagogastric junction (AEG) is still unclear, and no consensus exists whether to treat it as an esophageal cancer or as a gastric cancer, which would include adjuvant therapy [5]. The 10th edition of the guidelines for management of esophageal cancer in Japan provides separate guidelines for AEG [6]. The frequency of this type of adenocarcinoma is expected to increase in Japan, and advanced disease has a poor prognosis [7]. Procedures for the extent of esophageal resection and mediastinal or abdominal lymph node dissection remain controversial. A thoracic approach can successfully remove the mediastinal lymph node but may markedly reduce quality of life after surgery [8]. The 5-year survival rate in patients with superficially invasive adenocarcinoma confined to the mucosa and submucosa is unsatisfactory, and there is no consensus on whether to treat surgically in such cases $[9,10]$. We perform total gastrectomy for advanced AEG, but we think that minimally invasive surgery could be more appropriate for early-stage cases. However, there are few published studies of patients with early (T1) AEG.

A prospective nationwide multicenter study in Japan revealed that complete nodal clearance along the distal portion of the stomach offers marginal survival benefits for patients with AEG less than $4 \mathrm{~cm}$ in diameter. The optimal extent of esophageal resection and the benefits of mediastinal node dissection remain issues to be addressed in managing patients with esophagus-predominant AEG [11]. The purpose of this study was to determine the optimal range of resection and lymph node dissection for superficial and advanced Siewert type II AEG, considering lymph node metastases from AEG, and to develop a strategy for treatment that includes adjuvant therapy to improve the survival rate.

\section{Materials And Methods}

\subsection{Patients}

The patients were selected from a retrospective study by the Department of Surgery, Institute of Gastroenterological Surgery, Tokyo Women's Medical University, that was conducted from 1990 to 2019. We compared 88 cases of advanced AEG in patients who underwent surgery with lymph node dissection with 52 cases of superficial AEG, 23 of whom underwent endoscopic treatment (endoscopic mucosal resection [EMR] or endoscopic submucosal dissection [ESD]), and 29 of whom underwent surgery with lymph node dissection. All tumors fulfilled the criteria of histologically proven adenocarcinoma with the center located within $1 \mathrm{~cm}$ of the junction on the esophageal side or $2 \mathrm{~cm}$ on the gastric side (Siewert type II classification). We retrospectively investigated the patient characteristics, pathological findings, surgical procedures, optimum extent of lymph node dissection, location of metastatic lymph nodes, recurrence pattern, and survival curves. This study was approved by the ethics committee of Tokyo Women's Medical University in Tokyo Japan.

\subsection{Classification of the Clinical Evaluation}


The progression of the tumors was evaluated in accordance with the Union for Inter-national Cancer Control (UICC) and the American Joint Committee on Cancer (AJCC) guidelines for gastric carcinoma, 8th edition [12]. Lymph node station numbers and pathological responses after preoperative treatment were defined in accordance with the Japanese Classification of Gastric Carcinoma (14th edition) and the Japanese Classification of Esophageal Cancer (11th edition) [13]. The depth of tumor invasion was measured as $\mathrm{T} 1 \mathrm{a}$ ( $\mathrm{m} 1$, carcinoma in situ; $\mathrm{m} 2$, invasion to the lamina propria mucosa; or $\mathrm{m} 3$, muscularis mucosa) or T1b (invasion to but not beyond the submucosa; divided into three equal parts: sm1, sm2, and sm3). The macroscopic types were defined as type 0-Ip (pedunculated), 0-Is (sessile), 0-Ila (slightly elevated), 0-IIb (flat), 0-Ilc (slightly depressed), or 0-III (superficial and excavated). Lymphatic vessel invasion was expressed according to the degree of invasion: ly0 (no lymphatic invasion), ly1 (focal lymphatic invasion), ly2 (moderate lymphatic invasion), or ly3 (prominent lymphatic invasion). Blood vessel invasion was similarly expressed according to the degree of invasion: v0 (no vascular invasion), v1 (focal vascular invasion), v2 (moderate vascular invasion), or v3 (prominent vascular invasion). The number of regional lymph node stations was categorized in accordance with the Japanese Classification of Esophageal Cancer. The cervical lymph nodes consist of No.101 (Cervical paraesophageal lymph nodes) and No.104 (Supraclavicular lymph nodes). The upper thoracic lymph nodes consist of No.105 (Upper thoracic paraesophageal lymph nodes), 106 rec (Recurrent nerve lymph nodes), 106 tb (Tracheobronchial lymph nodes) and No. 106 P (Pretracheal lymph nodes). The middle thoracic lymph nodes consist of No.107 (Subcarinal lymph nodes), No.108 (Middle thoracic paraesophageal lymph nodes) and No.109 (Main bronchus lymph nodes). The lower thoracic lymph nodes consist of No.110 (Lower thoracic lymph nodes), No.111 (Supradiaphragmatic lymph nodes) and No.112 (Posterior mediastinal lymph nodes). The abdominal lymph nodes consist of No.1 (Right paracardial lymph nodes), No.2 (Left paracardial lymph nodes), No.3 (Lesser curvature lymph nodes), No.4 sa (Left greater curvature lymph nodes along the short gastric arteries), No.4 sb (Left greater curvature lymph nodes along the left gastroepiploic artery), No. $4 \mathrm{~d}$ (Right greater curvature lymph nodes along the right gastroepiploic artery), No. 5 (Suprapyloric lymph nodes), No.6 (Infrapyloric lymph nodes), No.7 (Lymph nodes at the root of the left gastric artery), No.8 a(Lymph nodes along the common hepatic artery), No.9 (Lymph nodes along the celiac artery), No10. (Lymph nodes along the splenic hilum), No.11 (Lymph nodes along the splenic artery), No.12 (Lymph nodes along the proper hepatic artery), No.16 (Paraaortic lymph nodes) and No.20 (Para esophageal lymph nodes at the esophageal hiatus of the diaphragm). Tumor histological classification was also evaluated in accordance with the Japanese Gastric Cancer Association [14], with well and moderately differentiated tubular adenocarcinoma and papillary adenocarcinoma classified as differentiated-type carcinomas, and poorly differentiated adenocarcinoma, signet ring cell carcinoma, and mucinous carcinoma classified as undifferentiated-type carcinomas. The Japanese Esophageal Society subclassification of Nishi's proposal has five types, depending on the relative extent of esophageal (E) or gastric (G) involvement (E, EG, E=G, GE, and G)

\subsection{Priority of Nodal Dissection}

To evaluate which nodes, have priority for dissection, we adopted a method using the therapeutic value index introduced by Sasako et al [15]. The index is calculated by multi-plying the frequency of metastasis 
to the station by the 3- or 5-year survival rate of patients with metastasis to that station. Nodes were a priority for dissection if the value of the index in the station had a metastatic incidence exceeding $5 \%$.

\subsection{Statistical Analyses}

All data are presented as the medians and total ranges unless otherwise stated. The survival was calculated by the Kaplan-Meier method and then compared between groups with the log-rank test. The hazard ratio of the survival was calculated with Cox proportional hazard analyses. $p<0.05$ was statistically significant.

\section{Results}

\subsection{Patient Characteristics}

Of the 140 total patients, 52 had superficial AEG and 88 had advanced AEG (Table 1) Positivity for H. pylori was $13.6 \%$ in superficial AEG and $29.8 \%$ in advanced AEG. This infections rate was lower than expected for same age group because the predicted prevalence (with $95 \% \mathrm{Cl}$ ) among those born in 1950 is $59.1 \%(58.2 \%-60.0 \%)$ [16]. Superficial AEG tumors had a high proportion of the GE subclassification, and advanced AEG tumors had a high proportion of EG. Barrett esophagus was found in $60 \%$ of those with superficial AEG and in $33 \%$ of those with advanced AEG. The number of patients with long-segment Barrett esophagus was low for both types. Multiple cancers were found in the stomachs of five patients with superficial AEG. Synchronous cancer was found in five cases of superfi-cial AEG and six of advanced AEG. Adjuvant (postoperative) chemotherapy was given to about half of the patients with advanced cancer. Preoperative (neoadjuvant) chemoradiotherapy has recently been introduced.

Table1 Clinical characteristics of the patients 


\begin{tabular}{|c|c|c|}
\hline Characteristic & Superficial $(n=52)$ & Advanced $(n=88)$ \\
\hline Age (years) & $68.5(33-84)$ & $64.5(34-87)$ \\
\hline \multicolumn{3}{|l|}{ Gender } \\
\hline Male & $45(87 \%)$ & $76(86 \%)$ \\
\hline Female & $7(13 \%)$ & $12(14 \%)$ \\
\hline H. pylori positive (\%) & $13.60 \%$ & $29.80 \%$ \\
\hline Tumor size (mm) & $23.9(5-80)$ & $62.3(19-114)$ \\
\hline \multicolumn{3}{|l|}{ Tumor location } \\
\hline EG & $15(29 \%)$ & $44(50 \%)$ \\
\hline$E=G$ & $6(11 \%)$ & $15(17 \%)$ \\
\hline GE & $31(60 \%)$ & $29(33 \%)$ \\
\hline \multicolumn{3}{|l|}{ Barrett's esophagus } \\
\hline$(+)$ & $31(60 \%)$ & $29(33 \%)$ \\
\hline$(-)$ & $21(40 \%)$ & $59(67 \%)$ \\
\hline Length of Barrett's esophagus (mm) & $14.8(0-80)$ & $27.8(5-60)$ \\
\hline Long-segment Barrett's esophagus & $7(14 \%)$ & $11(13 \%)$ \\
\hline Short-segment Barrett's esophagus) & $24(46 \%)$ & $18(20 \%)$ \\
\hline \multicolumn{3}{|l|}{ Macroscopic type } \\
\hline 0-Ip & 13 & \\
\hline 0 -Is & 4 & \\
\hline $0-$-lla & 19 & \\
\hline $0-\| l b$ & 1 & \\
\hline $0-\| c$ & 14 & \\
\hline $0-$-III & 1 & \\
\hline 1 & & 9 \\
\hline 2 & & 25 \\
\hline 3 & & 50 \\
\hline 4 & & 1 \\
\hline 5 & & 3 \\
\hline
\end{tabular}




\begin{tabular}{|c|c|c|}
\hline \multicolumn{3}{|l|}{ Clinical stage (UICC-AJCC 8th) } \\
\hline I & 47 & 0 \\
\hline$\| A$ & 4 & 0 \\
\hline IIB & 0 & 8 \\
\hline III & 0 & 79 \\
\hline IVA & 1 & 0 \\
\hline IVB & 0 & 1 \\
\hline \multicolumn{3}{|l|}{ Multiple cancer } \\
\hline Esophagus & 0 & 1 \\
\hline Stomach & 5 & 1 \\
\hline \multicolumn{3}{|l|}{ Synchronous cancer } \\
\hline Liver & 0 & 2 \\
\hline Lung & 1 & 1 \\
\hline Malignant lymphoma & 1 & 0 \\
\hline Rectum & 1 & 1 \\
\hline GIST & 1 & 1 \\
\hline Prostate & 0 & 1 \\
\hline Hypopharynx & 1 & 0 \\
\hline \multicolumn{3}{|l|}{ Adjuvant therapy } \\
\hline Neoadjuvant chemotherapy & 0 & $2(2 \%)$ \\
\hline Neoadjuvant chemoradiotherapy & 0 & $15(17 \%)$ \\
\hline Postoperative chemotherapy & $1(2 \%)$ & $45(51 \%)$ \\
\hline \multicolumn{3}{|l|}{ Surgical approach } \\
\hline Operation & 29 & 88 \\
\hline ESD or EMR & 23 & 0 \\
\hline
\end{tabular}

Abbreviations:

AJCC: American Joint Committee on Cancer

UICC: Union for International Cancer Control 
GIST: Gastrointestinal Stromal Tumor

EMR: endoscopic mucosal resection

ESD: endoscopic submucosal dissection

\subsection{Pathological findings and surgical Procedures}

Of the 52 patients with superficial AEG, 29 patients (56\%) underwent surgery, 23 patients (54\%) underwent ESD or EMR. In the 52 patients with superficial AEG, the depth of invasion was T1a in 15/23 of the patients with superficial AEG treated with ESD or EMR. Most of the surgical cases were T1b. Of the 29 patients who underwent surgery for superficial AEG, 5 had lymph node metastasis; the depth of invasion was sm2 in 4 patients and sm3 in 1 patient who had upper thoracic and lower thoracic lymph node metastases. Five patients in whom the tumor invaded to the submucosa received chemoradiotherapy or surgery as additional treatment. In superficial AEG, lymphatic vessel invasion was more common than vascular invasion. The proportion with undifferentiated histological type was higher in patients with advanced cancer than in those with superficial cancer. Most patients ( $90 \%$ with superficial AEG and $70 \%$ with advanced AEG) underwent lower esophagectomy + proximal gastrectomy. The surgical approach was transhiatal in $69 \%$ of those with superficial AEG and left thoracotomy in $56 \%$ of those with advanced AEG. Re-construction was performed with gastric tube in $55 \%$ of patients with superficial AEG and in $73 \%$ of patients with advanced AEG. Double-tract reconstruction was performed in $45 \%$ of cases of superficial AEG (Table2).

Table 2 Pathological findings and surgical treatment of patients 


\section{Parameters}

Depth of tumor invasion

T1a

$\begin{array}{lll}\mathrm{m} 1 & 1 & 0 \\ \mathrm{~m} 2 & 5 & 1 \\ \mathrm{~m} 3 & 9 & 6\end{array}$

T1b

$\mathrm{sm} 1$

sm2

sm3

T2

T3

$\mathrm{T} 4$

Degree of lymph node

metastasis

$\begin{array}{llll}\text { N0 } & 23 & 24 & 29 \\ \text { N1 } & 0 & \begin{array}{l}4(\text { all patients were } \\ \text { sm2) }\end{array} & 16 \\ \text { N2 } & 0 & 1(\mathrm{sm} 3) & 18 \\ \text { N3 } & 0 & 0 & 25\end{array}$

Pathological stage (UICC-AJCC

8th)

Stage IA

Stage IB

Stage IIA

Stage IIB

15

7

8

17

0
1
6
5
11
6

6
Advanced

operated $(n=88)$

Stage IIIA

Stage IIIB

Stage IVA

Stage IVB 


\begin{tabular}{|c|c|c|c|}
\hline ly0 & 19 & 15 & 7 \\
\hline ly1 & 3 & 8 & 33 \\
\hline ly2 & 0 & 4 & 28 \\
\hline ly3 & 1 & 2 & 20 \\
\hline \multicolumn{4}{|l|}{ Venous invasion } \\
\hline v0 & 22 & 25 & 28 \\
\hline v1 & 0 & 4 & 38 \\
\hline v2 & 1 & 0 & 16 \\
\hline v3 & 0 & 0 & 6 \\
\hline \multicolumn{4}{|l|}{ Histological grade } \\
\hline Differentiated-type carcinoma & 22 & $24(83 \%)$ & $55(63 \%)$ \\
\hline Undifferentiated-type carcinoma & 1 & $5(17 \%)$ & $33(37 \%)$ \\
\hline \multicolumn{4}{|l|}{ Type of surgery } \\
\hline Total gastrectomy & & $0(0 \%)$ & $6(7 \%)$ \\
\hline $\begin{array}{l}\text { Lower esophagectomy + } \\
\text { proximal gastrectomy }\end{array}$ & & $26(90 \%)$ & $62(70 \%)$ \\
\hline Subtotal esophagectomy & & $3(10 \%)$ & $20(23 \%)$ \\
\hline ESD or EMR & 23 & & \\
\hline \multicolumn{4}{|l|}{ Approach } \\
\hline Right thoracotomy & & $2(7 \%)$ & $20(23 \%)$ \\
\hline Left thoracotomy & & $7(24 \%)$ & $49(56 \%)$ \\
\hline Trans-hiatal & & $20(69 \%)$ & $19(21 \%)$ \\
\hline \multicolumn{4}{|l|}{ Reconstruction } \\
\hline Gastric tube & & $16(55 \%)$ & $64(73 \%)$ \\
\hline Jejunum & & $0(0 \%)$ & $0(0 \%)$ \\
\hline Double tract & & $13(45 \%)$ & $14(16 \%)$ \\
\hline Roux-Y & & $0(0 \%)$ & $6(7 \%)$ \\
\hline Colon & & $0(0 \%)$ & $4(4 \%)$ \\
\hline
\end{tabular}


Abbreviations: EMR-endoscopic mucosal resection, ESD-endoscopic submucosal dissection.

\subsection{Lymph Node Metastasis}

The calculated index for each nodal station in patients with advanced AEG was in stations 1, 2, 3, 7, 11 and 110 for 3-year survival and in stations 1, 2, 3 and 7 for 5-year survival (Table 3). We did not calculate the index for cervical, paraaortic lymph nodes and paraesophageal nodes at the esophageal hiatus of the diaphragm because only a few patients underwent dissection of these stations. The location of affected lymph nodes varied with the extent of esophageal involvement as well as with cancer stage (Table 4).

Table 3 Calculated index for each nodal station in advanced AEG 


\begin{tabular}{|c|c|c|c|c|c|}
\hline $\begin{array}{l}\text { Lymph } \\
\text { node } \\
\text { station }\end{array}$ & $\begin{array}{l}\text { Incidence of } \\
\text { lymph node } \\
\text { metastasis (\%) }\end{array}$ & $\begin{array}{l}\text { 3-year survival rate of } \\
\text { patients with metastatic } \\
\text { nodes (\%) }\end{array}$ & $\begin{array}{l}\text { IEBLD } \\
\text { of } 3 \\
\text { years }\end{array}$ & $\begin{array}{l}\text { 5-year survival rate of } \\
\text { patients with metastatic } \\
\text { nodes (\%) }\end{array}$ & $\begin{array}{l}\text { IEBLD } \\
\text { of } 5 \\
\text { years }\end{array}$ \\
\hline 1 & $32 / 88$ (36\%) & 32 & 11.64 & 15 & 5.45 \\
\hline 2 & $32 / 88$ (36\%) & 30 & 10.91 & 15 & 5.45 \\
\hline 3 & 31/88 (11\%) & 39 & 13.7 & 17 & 5.99 \\
\hline $4 \mathrm{sa}$ & $3 / 28$ (11\%) & 0 & 0 & 0 & 0 \\
\hline $4 s b$ & $0 / 13(0 \%)$ & 0 & 0 & 0 & 0 \\
\hline $4 d$ & 0/9 (0\%) & 0 & 0 & 0 & 0 \\
\hline 5 & 1/10 (10\%) & 23 & 2.3 & 23 & 2.3 \\
\hline 6 & $0 / 4(0 \%)$ & 0 & 0 & 0 & 0 \\
\hline 7 & $36 / 8(41 \%)$ & 30 & 12.27 & 13 & 5.32 \\
\hline $8 a$ & 6/38 (16\%) & 20 & 3.16 & 0 & 0 \\
\hline 9 & $5 / 36(14 \%)$ & 20 & 2.78 & 0 & 0 \\
\hline 10 & $0 / 9(0 \%)$ & 0 & 0 & 0 & 0 \\
\hline 11 & 5/34 (15\%) & 52 & 7.65 & 27 & 3.97 \\
\hline 12 & $3 / 8(38 \%)$ & 32 & 12 & 0 & 0 \\
\hline 16 & $3 / 6(50 \%)$ & 0 & 0 & 0 & 0 \\
\hline 20 & $3 / 7(16 \%)$ & 50 & 21.4 & 50 & 21.4 \\
\hline $101 R$ & 1/3 (33\%) & 0 & 0 & 0 & 0 \\
\hline 101L & $0 / 3(0 \%)$ & 0 & 0 & 0 & 0 \\
\hline 104R & 0/1 (0\%) & 0 & 0 & 0 & 0 \\
\hline 104L & $0 / 2$ (0\%) & 0 & 0 & 0 & 0 \\
\hline 105 & 2/13 (15\%) & 0 & 0 & 0 & 0 \\
\hline 106rR & 2/16 (13\%) & 0 & 0 & 0 & 0 \\
\hline 106rL & 2/16 (13\%) & 0 & 0 & 0 & 0 \\
\hline $106 P$ & 1/3 (33\%) & 0 & 0 & 0 & 0 \\
\hline 106tbR & 0/3 (0\%) & 0 & 0 & 0 & 0 \\
\hline 106tbL & 0/11 (0\%) & 0 & 0 & 0 & 0 \\
\hline 107 & 1/17 (6\%) & 0 & 0 & 0 & 0 \\
\hline
\end{tabular}




\begin{tabular}{|llllll|}
108 & $3 / 30(10 \%)$ & 0 & 0 & 0 & 0 \\
\hline $109 \mathrm{R}$ & $1 / 12(8 \%)$ & 0 & 0 & 0 & 0 \\
\hline $109 \mathrm{~L}$ & $1 / 17(6 \%)$ & 0 & 0 & 0 & 0 \\
110 & $13 / 70(19 \%)$ & 32 & 5.94 & 0 & 0 \\
111 & $5 / 32(17 \%)$ & 0 & 0 & 0 & 0 \\
112 & $4 / 35(11 \%)$ & 25 & 2.86 & 25 & 2.86 \\
\hline
\end{tabular}

Abbreviation: IEBLD: Index of Estimated Benefit from Lymph node Dissection

Table4 Relationship between esophageal involvement and metastatic lymph node

\begin{tabular}{|llllll|}
\hline \multicolumn{2}{|l|}{ Location of lymph node } & & & & \\
& Cervical & Upper & Middle & Lower & Abdominal \\
\hline $0-19 \mathrm{~mm}$ & & & & & \\
\hline Superficial $(\mathrm{n}=25)$ & 0 & 0 & 0 & 0 & 4 \\
\hline Advanced $(\mathrm{n}=22)$ & 0 & 0 & 0 & 2 & 12 \\
\hline $20-39 \mathrm{~mm}$ & & & & & \\
\hline Superficial $(n=3)$ & 0 & 1 & 1 & 0 & 1 \\
\hline Advanced $(n=37)$ & 1 & 0 & 0 & 5 & 24 \\
\hline 40 mm $<$ & & & & & \\
\hline Superficial $(n=1)$ & 0 & 0 & 0 & 0 & 0 \\
\hline Advanced $(n=29)$ & 0 & 2 & 5 & 9 & 16 \\
\hline
\end{tabular}

Abbreviation:

Cervical: Cervical lymph nodes $(101,104)$

Upper: Upper thoracic lymph nodes $(105,106)$

Middle: Middle thoracic lymph bodes $(107,108,109)$

Lower: Lower thoracic lymph bodes $(110,111,112)$

Abdominal: Abdominal lymph nodes $(1,2,3,7,8,9,10,11,12,16,20)$

\subsection{Survival}


The median follow-up was 1476 days (range 125-4549). The 5 -year overall survival rates were $88 \%$ for patients treated with ESD, $78 \%$ for those with superficial AEG who under-went surgery, and $24 \%$ for those with advanced AEG ( $p=0.011$; Fig. 1$)$. Only two patients with superficial AEG experienced lymph node metastasis after surgery, but 13 patients with advanced AEG had metastases to thoracic lymph nodes and 12 had metastases to abdominal lymph nodes after surgery. Despite of lymph node dissection, twenty-five patients experienced lymph node metastasis after operation in advanced AEG and there were many disseminations in advanced AEG (Table5).

Table 5 Locations of recurrence

\begin{tabular}{|c|c|c|c|}
\hline Parameters & $\begin{array}{l}\text { Superficial, ESD/EMR ( } n= \\
23)\end{array}$ & $\begin{array}{l}\text { Superficial, operated }(n= \\
29)\end{array}$ & $\begin{array}{l}\text { Advanced, operated ( } n= \\
\text { 88) }\end{array}$ \\
\hline \multicolumn{4}{|l|}{ Lymph node } \\
\hline Cervical & 0 & 0 & 0 \\
\hline Mediastinal & 0 & 0 & 13 \\
\hline Abdominal & 1 & 1 & 12 \\
\hline Dissemination & 1 & 1 & 18 \\
\hline Liver & 1 & 2 & 14 \\
\hline Lung & 0 & 1 & 4 \\
\hline Bone & 0 & 0 & 4 \\
\hline Brain & 0 & 0 & 3 \\
\hline Others & 0 & 0 & 2 \\
\hline
\end{tabular}

\subsection{Neoadjuvant Chemoradiotherapy}

There were no differences in survival between patients who received postoperative adjuvant therapy with S-1 for advanced AEG and those who received surgery alone ( $p=0.5192 ;$ Fig.2). We selected new neoadjuvant therapy for the following reasons. 1. The effect of the S-1 as a postoperative adjuvant therapy was insufficient (Figure 2). 2. It seems that radiation therapy was more effective because there was dissemination after operation as a pattern of recurrence (Table 5). 3. The nab-paclitaxel was reported in a gastric cancer preclinical model with subcutaneous and peritoneal xenografts, comparing with paclitaxel [17-19]. We have started a Phase I trial of nab-paclitaxel combined with radiotherapy for advanced AEG (registration number UMIN000024088) to compare the efficacy of low-dose nab-paclitaxel with the current standard dose $(260 \mathrm{mg} / \mathrm{m} 2)$ of nab-paclitaxel as first- or second-line chemotherapy for advanced AEG. The radiotherapy targets lymph node stations 110, 1, 2, 3, 7 and 11. Enrollment of patients was started at level 1 , and the three patients at this starting dose level experienced no dose 
limiting toxicity (DLT). Enrollment at level 2 was started in accordance with the specified procedure for progression to the next level. At level 2, one of three enrolled patients experienced treatment-related adverse events corresponding to DLT. These treatment-related adverse events were grade 1 peripheral neuropathy. Enrollment at level 3 was started in accordance with the specified procedure for progression to the next level. These treatment-related adverse events were grade 3 peripheral neuropathy and grade 4 Febrile neutropenia. An additional three patients were enrolled at level 2, but none experienced treatmentrelated adverse events corresponding to DLT, thus leading to the recommended dose was level 2 (Fig.3).

In this study 14 patients have performed nab-paclitaxel combined with radiotherapy as neoadjuvant therapy for advanced AEG. Tumor grade after treatment for evaluation of therapeutic effectiveness would be achieving a grade> $1 \mathrm{~b}$ was considered evidence of effectiveness. When therapeutic efficacy was evaluated, 13 patients in 14 were at Grade 1b or higher (table.6), but there were no differences in OS between the group that received neoadjuvant chemoradiotherapy and the group that received preoperative chemotherapy with S-1 ( $p=0.5908$; Fig.4), because the patients who received neoadjuvant chemoradiotherapy was too much small numbers. Because of the nature of a phase I trial and the small number of patients enrolled, it is not appropriate to draw meaningful conclusions concerning overall response rate (ORR) or survival.

Table 6 The result of nab-paclitaxel combined with radiotherapy for advanced AEG

\begin{tabular}{|llllllll|}
\hline Patients & Age & Gender & Stage & Dose & RT(Gy) & Response & $\begin{array}{l}\text { Evaluation therapeutic } \\
\text { effectiveness }\end{array}$ \\
\hline 1. & 51 & Male & IIB & 120 & 39.6 & PR & 1b \\
\hline 2. & 55 & Male & IIB & 120 & 39.6 & PR & 2 \\
\hline 3. & 76 & Male & IIB & 120 & 39.6 & PR & 2 \\
\hline 4. & 56 & Male & IIB & 150 & 39.6 & PR & 2 \\
\hline 5. & 49 & Male & III & 150 & 39.6 & PR & $1 \mathrm{~b}$ \\
\hline 6. & 45 & Male & III & 150 & 39.6 & PR & 2 \\
\hline 7. & 64 & Male & III & 180 & 39.6 & PR & 2 \\
\hline 8. & 45 & Male & IVA & 180 & 39.6 & PR & $1 \mathrm{~b}$ \\
\hline 9. & 64 & Male & III & 180 & 39.6 & PR & 2 \\
\hline 10. & 59 & Male & IVA & 150 & 39.6 & PR & $1 \mathrm{~b}$ \\
\hline 11. & 65 & Male & III & 150 & 39.6 & SD & $1 \mathrm{a}$ \\
\hline 12. & 63 & Male & III & 150 & 39.6 & PR & 1b \\
\hline 13. & 47 & Male & III & 150 & 39.6 & PR & 2 \\
\hline 14. & 48 & Male & III & 150 & 39.6 & CR & 3 \\
\hline
\end{tabular}




\section{Discussion}

There are some differences in standard treatment for AEG between European and Japanese guidelines. In Western countries, the definition of the esophagogastric junction (EGJ) is the oral end of the fold on the greater curvature of the stomach, according to the Prague classification. In Japan, the definition is the lower end of the esophageal palisade vessels. For carcinoma of the esophagogastric junction, in Western countries the Siewert classification is that type I tumors (lower-esophageal adenocarcinoma) are located $1-5 \mathrm{~cm}$ above the EGJ, irrespective of EGJ involvement; type II tumors (cardia adenocarcinoma) are located between $1 \mathrm{~cm}$ above and $2 \mathrm{~cm}$ below the EGJ; and type III tumors (subcardial gastric adenocarcinoma) are located $2-5 \mathrm{~cm}$ below the EGJ with involvement of the EGJ and distal esophagus [20]. In Japan, the Japanese Classification of Esophageal Cancer and Gastric Cancer uses Nishi's classification to define five types of EGJ cancer characterized by diameters of $\leq 40 \mathrm{~mm}$ and an epicenter within $2 \mathrm{~cm}$ proximal or distal to the EGJ, irrespective of histological type [21]. The location of the center of the tumor is about the same in Siewert type II and the Nishi classification. In histology, the Nishi classification includes squamous carcinoma, but the Siewert classification does not.

For Siewert type II AEG, or similar tumors classified as Nishi EG, E=G, or GE, the type of surgical resection and reconstruction should be individualized [22]. Two randomized controlled trials have compared surgical procedures for EGJ cancer. One was a trial in the Netherlands comparing right thoracotomy versus a transhiatal approach; the survival of patients with Siewert type II did not differ by approach, but respiratory complications were significantly higher in the thoracotomy group [23]. The other trial, in Japan, obtained the same results as the Dutch trial [24]. Therefore, in Japan we perform low esophagectomy and total gastrectomy through a transhiatal approach for Siewert type II AEG, as in Western countries.

The distance from the EGJ to the proximal edge of the primary tumor may be a significant indicator of metastasis or recurrence in the mediastinal lymph nodes in patients with Siewert type II tumors. Thorough mediastinal lymph node dissection via a transthoracic approach may provide a therapeutic benefit when the distance is $>3 \mathrm{~cm}$ [25]. In Japan, a prospective nationwide multicenter study determined that dissecting only station 110 was sufficient in cases of an EGJ tumor unless esophageal involvement exceeded $4.0 \mathrm{~cm}$ [26]. Although surgical procedures of superficial and locally advanced AEG are standardized, the role of adjuvant therapy for AEG is still controversial. In Japan, according to the results of the ACTS-GC trial in gastric cancer [27], we performed chemotherapy with S-1 as a postoperative adjuvant therapy. Recently, some institutes have begun using S-1 + docetaxcel or S-1 + oxaliplatin, based on the results of the START-2 trial $[28,29]$. Two trials in Europe have provided evidence for adjuvant therapy. The CROSS trial from the Netherlands showed that preoperative chemoradiotherapy improved survival among patients with potentially curable EGJ cancer. The regimen was associated with acceptable ad-verse-event rates [30]. The FLOT4 trial from Germany showed that overall survival was higher in the fluorouracil, leucovorin, oxaliplatin, docetaxel (FLOT) group than in the epirubicin and 
cisplatin plus either 5-FU or capecitabine (ECF/ECX) group [31]. Based on these Western trials, preoperative chemoradiotherapy with carboplatin + docetaxel and as a neoadjuvant and adjuvant chemotherapy with fluorouracil + leucovorin, oxaliplatin, and docetaxel is now standard therapy. We have introduced preoperative chemoradiotherapy at our institute because dissemination after surgery was a frequent and recurrent pattern. According to the report from Western population, Peritoneal or pleural recurrence rate were 5-15\% [32,33]. In Japan including our report these rates were more than $30 \%$. This data is exactly the basis for adjuvant chemoradiotherapy. In a phase 1 study, the primary objective was to determine the maximum tolerated dose (MTD) and recommended dose (RD) of nab-paclitaxel plus radiotherapy. The study was designed in accordance with a standard $3+3$ methods. This study was approved by the ethics commit-tee of Tokyo Women's Medical University in Tokyo Japan. We select nabpaclitaxel as a drug with a radiation expecting a high response. Nab-paclitaxel show higher response than solvent-base paclitaxel in two Phase III trial. One trial in advanced non-small-cell lung cancer compared nab-paclitaxel plus carboplatin with solvent-based paclitaxel plus carboplatin. Response rate for nab-paclitaxel group is 35\%, and solvent-base paclitaxel is $27 \%$ [34]. Second trial in previously treated advanced gastric cancer compared nab-paclitaxel with solvent-based paclitaxel. Response rate for nabpaclitaxel alone is $33 \%$, and solvent-base paclitaxel alone is $24 \%$ [35]. Furthermore, some data suggest that nab-paclitaxel is more effective than solvent-base paclitaxel in patients with peritoneal metastasis. In a subgroup analysis of Phase III trial in gastric cancer, overall survival, and progression-free survival in patients with peritoneal metastasis were better with nab-paclitaxel than with solvent-based paclitaxel. And a previous preclinical study showed that intravenous nab-paclitaxel is more effective than solventbased paclitaxel in a gastric cancer model with subcutaneous and peritoneal xenografts [19]. For these rea-sons, we select nab-paclitaxel. The RD was determined as level 2 (nab-paclitaxel $150 \mathrm{mg} / \mathrm{m} 2$ day1 and day $21+$ radiotherapy $39.6 \mathrm{~Gy}$ ). The results of this study are being sub-mitted to the journal and have not yet been published. The long-term safety and efficacy of this combination therapy will be evaluated in phase II trial. The preoperative chemoradiotherapy for AEG is slightly not popular in Japan because there were many complications after operation to receive radiation. The recommendation of combined taxane based chemotherapy and radiotherapy for advanced stage cases is not supported by the presented data.

\section{Conclusions}

In this retrospective study, we found that the optimal lymph node resection for advanced AEG consists of lymph nodes of the inferior mediastinum (No. 110), the lesser curvature (Nos. 1, 3, 7), No. 2, and No 11. Lymphadenectomy of lymph node stations $1,3,7$, and 11 was sufficient to improve survival of patients with superficial AEG except in case of thoracic lymph node metastasis can be confirmed before surgery. When esophageal involvement was $>40 \mathrm{~mm}$, we performed esophagectomy including upper thoracic lymph nodes in advanced AEG. Because the rate of metastasis to the thoracic lymph nodes is low in superficial AEG, a surgical procedure that removes the upper edge of the tumor should be selected. We were not satisfied with the result of surgical treatment including lymph node dissection alone in advanced AEG. We will recommend nab-paclitaxel combined with radiotherapy for advanced AEG to improve the survival rate. 


\section{Declarations}

Author Contributions: Conceptualization, Dr. Kosuke Narumiya and Dr. Harushi Osugi, Methodology, Dr. Kosuke Narumiya, Software, Dr. Kenji Kudo, Validation, Dr. Kosuke Narumiya, Dr. Kudo Kenji, Dr. Shinsuke Maeda, Formal Analysis, Dr. Yosuke Yagawa, Investigation, Dr. Kosuke Narumiya, Resources, Dr. Yukinori Toyoshima, Data Curation, Dr. Kyohei Ogawa, Writing - Original Draft Preparation, Dr. Kosuke Narumiya, Writing - Review \& Editing, Dr. Kosuke Narumiya, Visualization, Dr. Kosuke Narumiya, Supervision, Dr Hiroto Egawa, Project Administration, Dr Hiroto Egawa, Funding Acquisition, Dr. Kosuke Narumiya

Ethics approval and consent to participate: The study was conducted according to the guidelines of the Declaration of Helsinki and approved by the Ethics Committee of Tokyo Women's Medical University, Approval No. 4278). Informed consent was obtained from all subjects involved in the study.

\section{Consent for publication}

Written informed consent was obtained from the patients for publication of this article.

\section{1 accompanying images}

Data Availability Statement: All data generated or analyzed during this study are included in this published article [and its supplementary information files].

Competing interests: The authors declare that they have no competing interests.

Funding: This research received no external funding. The authors declare that they have no competing interests.

Conflicts of Interest: The authors declare no conflicts of interest.

Acknowledgments: The authors would like to thank the study coordinator Prof. Hiroko Ide for her support in this work.

\section{References}

1. Lagergren J, Bergström R, Lindgren A, Nyrén O. Symptomatic gastroesophageal reflux as a risk factor for esophageal adenocarcinoma. N. Engl. J. Med. 1999;340: 825-831.

2. Oda I, Abe S, Kusano C, Suzuki H, Nonaka S, Yoshinaga S, et al. Correlation between endoscopic type and invasion depth for early esophagogastric junction adenocarcinoma. Gastric Cancer. 2011; 14: 22-27.

3. Shibata A, Matsuda T, Ajiki W, Sobue T. Trend in incidence of adenocarcinoma of the esophagus in Japan, 1993-2001. Jpn J Clin Oncol. 2008; 38: 464-468. doi: 10.1093/jjco/hyn064.

4. Hongo M, Shoji T. Epidemiology of reflux disease and CLE in East Asia. J Gastroenterol. 2003; 38: 2530. 
5. SuhYS, Han DS, Kong SH, Lee HJ, Kim YT, Kim WH, et al. Should adenocarcinoma of the esophagogastric junction be classified as esophageal cancer? A comparative analysis according to the seventh AJCC TMN classification. Ann Surg.2012; 255: 905-915.

6. Japanese Classification of Esophageal Cancer. The Japan Esophageal Society. Kanehara and Co., Ltd., Tokyo. 2008 (the 10th Edition)

7. Lieberman MD, Shriver CD, Bleckner S, Burt M. Carcinoma of the esophagus prognostic significance of histologic type. J Thorac Cardiovasc Surg. 1995; 109:130-138.

8. Matsuda T, Takeuchi H, Tsuwano S, Nakamura R, Takahashi T, Wada N, et al. Optimal surgical management for esophagogastric junction carcinoma. Gen Thorac Cardiovasc Surg. 2014; 62: 560566.

9. Rice TW, Blackstone EH, Adelstein DJ, Zuccaro G Jr, Vargo JJ, Goldblum JR, et al. Role of clinically determined depth of tumor invasion in the treatment of esophageal carcinoma. J Thorac Cardiovasc Surg.2003; 125: 1091-1102.

10. Rice TW, Blackstone EH, Rybicki LA, Adelstein DJ, Murthy SC, DeCamp MM, et al. Refining esophageal cancer staging. J Thorac Cardiovasc Surg. 2003; 125: 1103-1113.

11. Yamashita H, Seto Y, Sano T, Makuuchi H, Ando N, Sasako M. Japanese Gastric Cancer Association and the Japan Esophageal Society. Results of a nationwide retrospective study of lymphadenectomy for esophagogastric junc-tion carcinoma. Gastric Cancer.2017; 20: 69-83. doi: 10.1007/s10120-0160663-8.PMID: 27796514

12. American Joint Committee on Cancer. AJCC Cancer Staging manual, $8^{\text {th }}$ edition. 2017

13. Japan Esophageal Society. Japanese classification of esophageal cancer, 11th edition: part I. Esophagus.2017; 14: 1-36.

14. Japanese Gastric Cancer Association. Japanese classification of gastric carcinoma: 3rd English edition. Gastric Cancer. 2011; 14: 101-112.

15. Sasako M, McCulloch P, Kinoshita T, Maruyama K. New method to evaluate the therapeutic value of lymph node dissection for gastric cancer. Br J Surg. 1995; 82: 346-351.

16. Wang C, Nishiyama T, Kikuchi S, Inoue M, Sawada N, Tsugane S, et al. Changing trends in the prevalence of H. pylori infection in Japan (1908-2003): a systematic review and meta-regression analysis of 170,752 individuals. Scientific reports. 2017; 14. 15491. doi: 10.1038/s41598-017-154907.

17. Xu H, Zhang L, Miao J, Liu S, Liu H, Jia T, et al. Patterns of recurrence in adenocarcinoma of the esophagogastric junction: a retrospective study. World J Surg Oncol. 2020 Jun 27;18(1):144. doi: 10.1186/s12957-020-01917-5. PMID: 32593312

18. Sasaki Y, Nishina T, Yasui H, Goto M, Muro K, Tsuji A, et al. Phase II trial of nanoparticle albuminbound paclitaxel as second-line chemotherapy for unresectable or recurrent gastric cancer. Cancer Sci. 2014; 105:812-817. doi: 10.1111/cas.12419. 
19. Takashima A, Shitara K, Fujitani K, Koeda K, Hara H, Nakayama N, et al. Peritoneal metastasis as a predictive factor for nab-paclitaxel in patients with pretreated advanced gastric cancer: an exploratory analysis of the phase III ABSOLUTE trial. Gastric Cancer. 2019; 22:155-163. doi: 10.1007/s10120-018-0838-6. Epub 2018 May 31. PMID: 29855738

20. Siewert JR, Stein HJ. Classification of adenocarcinoma of the oesophagogastric junction. Br J Surg. 1998; 85: 1457-1459.

21. Nishi M, Akune T. Cardia cancer-proposal of cancer in the esophagogastric junction (in Japanese). Geka Shinryo (Surg Diagn Treat). 1973; 15: 1328-1338.

22. Hölscher, AH., Law, S. Correction to: Esophagogastric junction adenocarcinomas: individualization of resection with special considerations for Siewert type II, and Nishi types EG, E = G and GE cancers. Gastric Cancer.2020; 23: 3-9. doi: 10.1007/s10120-019-01022-x. Epub 2019 Nov 6. PMID: 31691875

23. Hulscher JB, van Sandick JW, de Boer AG, Wijnhoven BP, Tijssen JG, Fockens P, et al. Extended transthoracic resection compared with limited transhiatal resection for adenocarcinoma of the esophagus. N Engl J Med. 2002; 347: 1662-1669.

24. Sasako M, Sano T, Yamamoto S, Sairenji M, Arai K, Kinoshita T, et al. Left thoracoabdominal approach versus abdomi nal transhiatal approach for gastric cancer of the cardia or subcardia; a randomised con trolled trial. Lancet Oncol. 2006; 7: 644-651.

25. Kurokawa Y, Hiki N, Yoshikawa T, Kishi K, Ito Y, Ohi M, et al. Mediastinal lymph node metastasis and recurrence in adenocarcinoma of the esophagogastric junction. Surgery. 2015; 157: 551-555.

26. Kurokawa Y, Takeuchi H, Doki Y, Mine S, Terashima M, Yasuda T, et al. Mapping of Lymph Node Metastasis from Esophagogastric Junction Tumors. A prospective Nationwide Multicenter Study. Ann Surg. 2021; 274: 120-127. doi: 10.1097/SLA.0000000000003499.

27. Sakuramoto S, Sasako M, Yamaguchi T, Kinoshita T, Fujii M, Nashimoto A, et al. ACTS-GC Group. Adjuvant chemotherapy for gastric cancer with S-1, an oral fluoropyrimidine. N Eng J Med. 2007; 357: 1810-1820.

28. Yoshida K, Kodera Y, Kochi M, Ichikawa W, Kakeji Y, Sano T, et al. Addition of Docetaxel to Oral Fluoropyrimidine Improves Efficacy in Patients With Stage III Gastric Cancer. Interm Analysis of JACCROGC-07, a Randomized Controlled Trial. J Clin Oncol. 2019; 37: 1296-1304.

29. Yamada Y, Higuchi K, Nishikawa K, Gotoh M, Fuse N, Sugimoto N, et al. Phase III study comparing oxaliplatin plus S-1 with cisplatin plus S-1 in chemotherapy-naïve patients with advanced gastric cancer. Ann Oncol. 2015; 26: 141-148.

30. Van Hagen P, Hulshof MC, van Lanschot JJ, Steyerberg EW, van Berge He-negouwen MI, Wijnhoven BP, et al. CROSS Group. Preoperative chemoradiotherapy for esophageal or junctional cancer. N Eng J Med. 2012; 366: 2074-2084.

31. Al-Batran SE, Homann N, Pauligk C, Goetze TO, Meiler J, Kasper S, et al. FLOT4-AIO Investigators. Perioperative chemotherapy with fluorouracil plus leucovorin, oxaliplatin, and docetaxel versus fluorouracil or capecitabine plus cisplatin and epirubicin for locally advanced, resectable gastric or 
gastroesophageal junction adenocarcinoma (FLOT4): a randomised, phase 2/3 trial. Lancet.2019; 11: 1948-1957. doi: 10.1016/S0140-6736(18)32557-1. Epub 2019 Apr 11. PMID: 30982686

32. Suh YS, Lee KG, Oh SY, Kong SH, Lee HJ, Kim WH, et al. Recurrence Pattern and Lymph Node Metastasis of Adenocarcinoma at the Esophagogastric Junction. Ann Surg Oncol. 2017 Nov;24(12):3631-3639. doi: 10.1245/s10434-017-6011-3. Epub 2017 Aug 21. PMID: 28828728

33. Kinoshita J, Fushida S, Tsukada T, Oyama K, Watanabe T, Shoji M, et al. Comparative study of the antitumor activity of Nab-paclitaxel and intraperitoneal solvent-based paclitaxel regarding peritoneal metastasis in gastric cancer. Oncol Rep. 2014;32(1):89-96. doi: 10.3892/or.2014.3210.

34. Langer CJ, Hirsh V, Ko A, Renschler MF, Socinsk, MA. Weekly nab-paclitaxel in combination with carboplatin as first-line therapy in patients with advanced non-small-cell lung cancer: analysis of safety and efficacy in patients with renal impairment. Clin Lung Cancer.2015; 16: 112-120. doi: 10.1016/j.cllc.2014.09.003. Epub 2014 Sep 30. PMID: 25572008

35. Shitara K, Takashima A, Fujitani K, Koeda K, Hara H, Nakayama N, et al. Nab-paclitaxel versus solvent-based paclitaxel in patients with previously treated advanced gastric cancer (ABSOLUTE): an open-label, randomised, non-inferiority, phase 3 trial. Lancet Gastroenterol Hepatol. 2017; 2: 277-287. doi: 10.1016/S2468-1253(16)30219-9. Epub 2017 Jan 19. PMID: 28404157

\section{Figures}




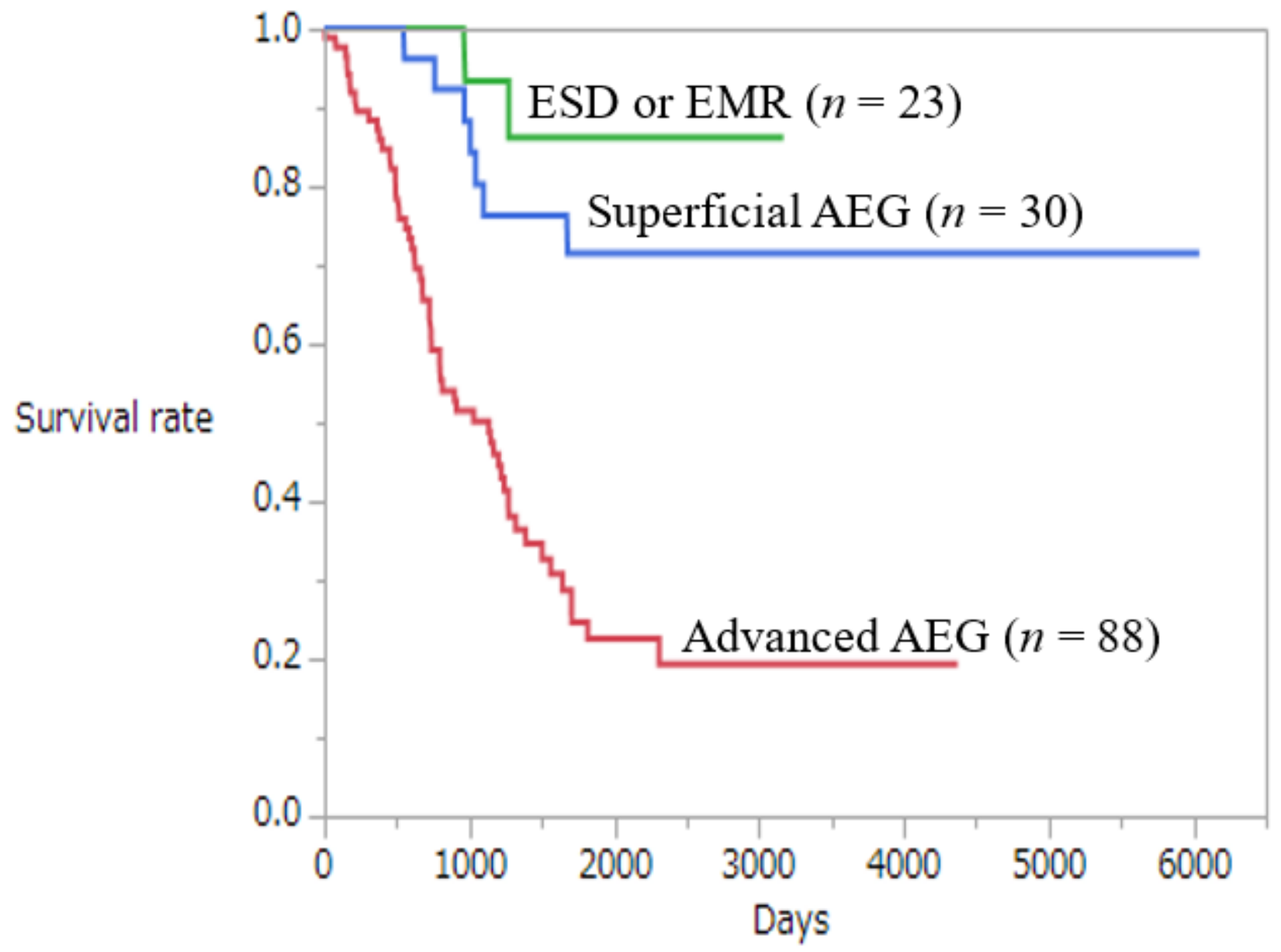

Figure 1

Kaplan-Meier survival curves comparing ESD or EMR, superficial AEG and advanced AEG. 


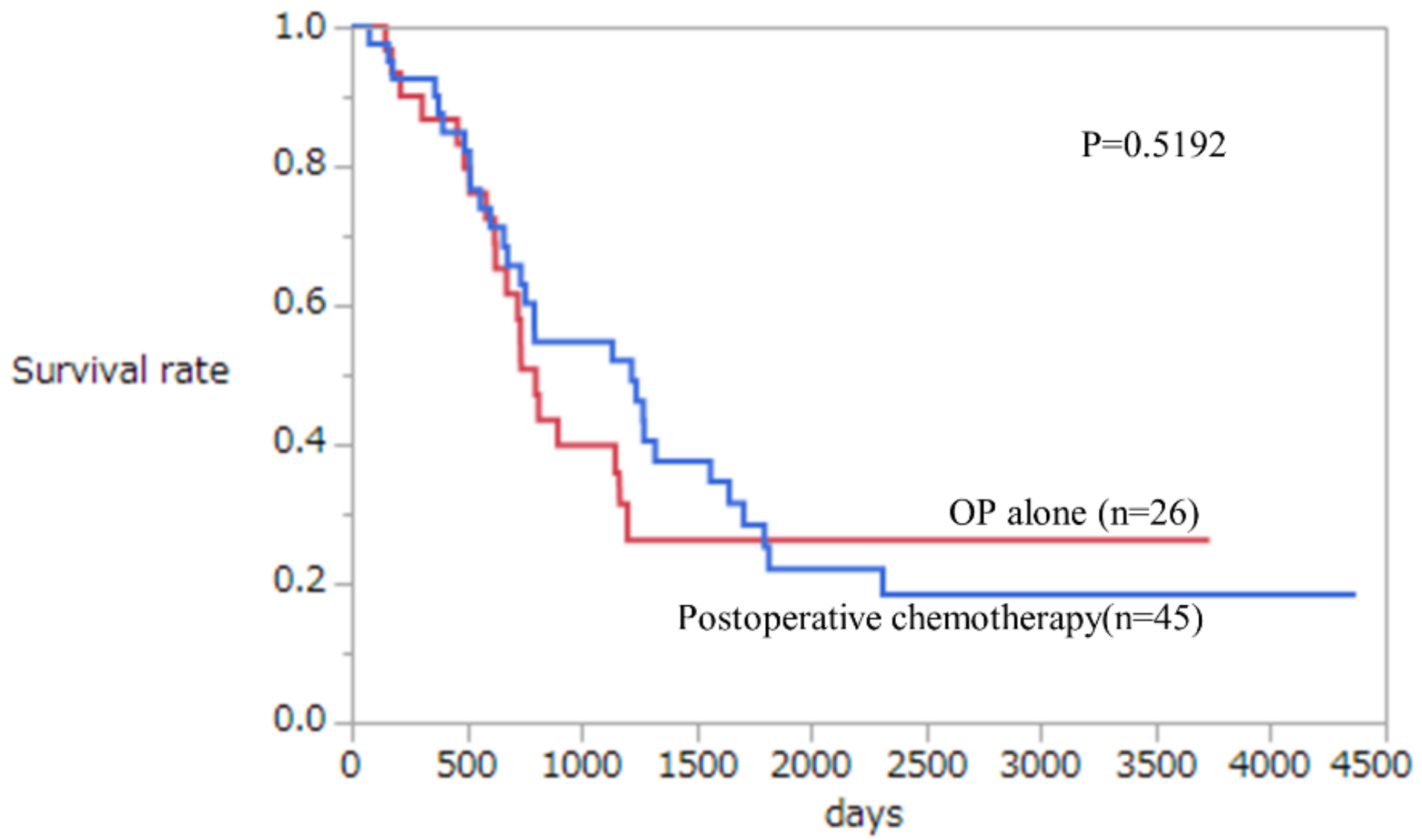

Figure 2

Five-year overall survival of patients receiving postoperative chemotherapy with S-1 for AEG or receiving sur-gery (OP) alone.

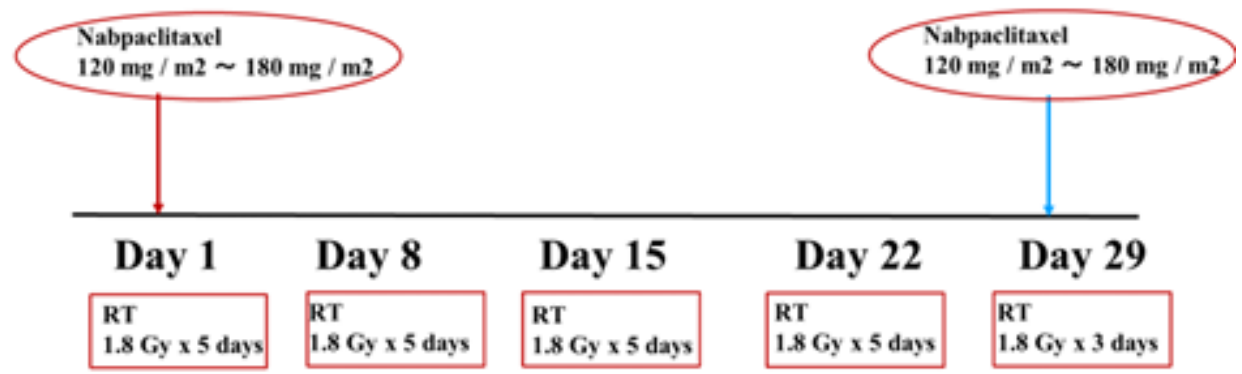

Maximum tolerated dose of Nabpaclitaxel

Level $0 \quad 100 \mathrm{mg} / \mathrm{m} 2$

Level $1120 \mathrm{mg} / \mathrm{m} 2$

Level $2150 \mathrm{mg} / \mathrm{m} 2$

Level $3180 \mathrm{mg} / \mathrm{m} 2$

Level $4220 \mathrm{mg} / \mathrm{m} 2$

RD: Recommended dose 
Figure 3

Phase I trial of Nab-Paclitaxel combined with radiotherapy for advanced AEG

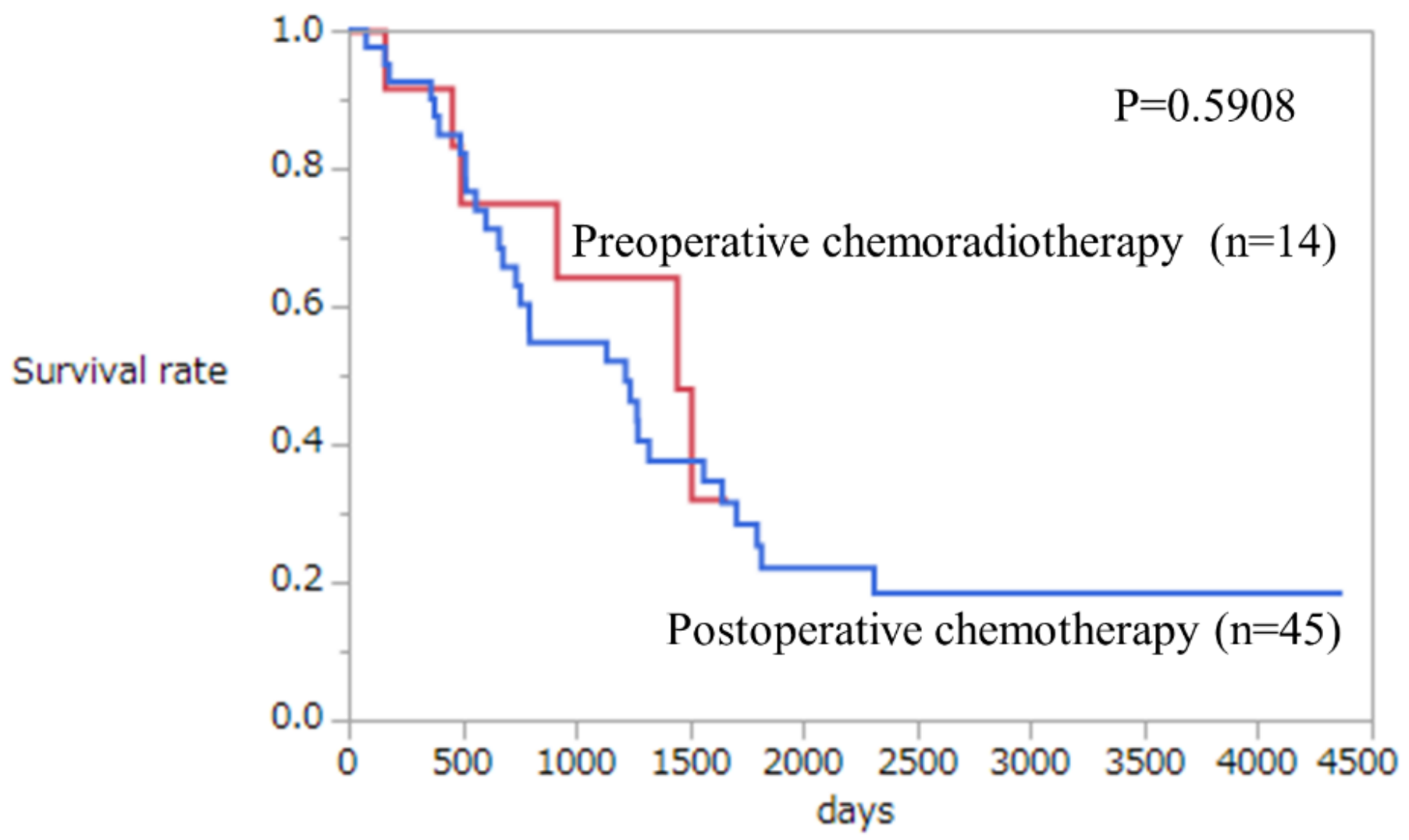

Figure 4

Overall survival of patients receiving neoadjuvant chemoradiotherapy or postoperative chemotherapy with S-1. 